\title{
The method for calculation and optimization of parameters of synchronous electric machines with permanent magnets as part of the generating and driving complexes
}

\author{
A R Safin*, I $V$ Ivshin and $T I$ Petrov \\ Kazan State Power Engineering University, Kazan, Russia
}

\begin{abstract}
New methodical solutions have been developed in the field of creating energy-efficient synchronous electrical machines with permanent magnets, designed to generate electrical energy as part of autonomous power plants and to drive various mechanisms.
\end{abstract}

\section{Introduction}

Synchronous electric machines with permanent magnets are increasingly often used in various technical complexes.

These machines are used in areas where traditionally DC motors or asynchronous motors have been used, such as driving circular pumps, driving compressors in refrigeration technology, ventilation systems, drilling rigs, and oil production [1].

The paper proposes a modern method for designing and optimizing synchronous machines using a genetic algorithm. An algorithm for analysis, multicriteria and topological optimization of rotors and inductors of machines with permanent magnets was developed [2],[3].

There are several design methods for optimizing electrical machines and electromagnetic devices. However, most of these methods are limited by optimizing several parameters that define the shape. In this regard, the structure topology design of an electrical machine in a given space should be promising for achieving an optimal project. Topological optimization allows us to get the original conceptual structure, while having minimal information about the structure of the object. Topological optimization methods were proposed about 20 years ago and turned out to be very promising [4].

Most of the previously mentioned methods for obtaining the optimal distribution of material suffer from significant computational costs. Either they use classical continuous optimization methods with intermediate material properties in combination with a solidification process, or they use a set level method to increase the distribution of material over a certain cell, which requires some local gradient information, or search through genetic algorithms and simulated annealing [5], [6].

\section{Topological optimization}

A method of topological optimization is proposed. The sample rotor design area is discretized in a finite element grid, and the material of several elements is defined as a gene in the chromosome. The method involves the use of more than two materials, namely: air, steel, and R, Xoriented magnets (radial and axial magnetization). It was proposed to introduce the concept of a cluster of many types of materials into genetic algorithms. If the cluster is small, that is, the number of cells in the area is less than or equal to an integer number Nmin, the cleaning procedure is performed [7].

The cleaning procedure can remove a small cluster of materials. Therefore, the structure obtained without considering the cleaning procedure contains many small pieces of iron in the magnet and numerous air cavities in iron [8].

The purpose of optimization is to limit the volume of permanent machines and determine the structure of rotor or inductor with the highest electromagnetic moment (force).

The calculation of synchronous machine parameters at the preliminary stage is carried out using various software. A database management system based on Microsoft Excel was developed for effective collaboration, data exchange between Matlab/Simulink, CATIA V5 and COMSOL Multiphysics and optimization of machine parameters.

The database management and optimization system allows performing the following actions [9],[10]:

- Input of parameters for numerical calculation and simulation modeling of autonomous power plant systems. Parameters can be entered as constant values, or variable values with a specified range of variation. This greatly simplifies the input of parameters through a single Excel spreadsheet workspace.

\footnotetext{
*Corresponding author: sarkazan@bk.ru
} 
- Software management through a database management system based on a specially written program simplifies numerical calculations and simulation modeling, as it makes it is possible not to enter control commands directly into the connected software.

- All data obtained during numerical calculations and simulation modeling is stored in a database, which makes it possible in the event of an error to save data, diagnose the system and improve the reliability of the system.

- Graphical visualization of the calculation results can significantly reduce the time to select the optimal or rational parameters.

- The ability to automatically build a threedimensional model of the object at the end of the calculations.

- Flexibility of the control system allows entering additional parameters for more complete calculations.

During development of numerical modeling, emphasis was placed on deep parametrization of the geometry of the translator and stator to study a large number of possible configurations of the geometry of an electrical machine [11]. This allows us to assess the impact of individual geometric parameters on the energy efficiency and to modernize the machine model to new requirements.

A method for multicriteria optimization of the structural dimensions of the stator, rotor and inductor according to the criterion of maximum generated power is proposed [12].

The task of optimizing the objective function is solved in the Matlab Optimization Toolbox application [13]. Matlab was used to write a program that allows calculating the parameters of the objective function based on a genetic algorithm.

In the proposed method, when performing optimization based on a genetic algorithm, the starting construction of components and parts of the action machine is taken from the results of multi-criteria optimization, then segmentation of elements of an autonomous power plant in vertical and horizontal directions (2D image) is performed [14]. The symmetry of the structure is taken into account to reduce the amount of computational operations. The functional principle of genetic algorithms consists in the identification of each element of an autonomous power plant with a unique binary code, including various options of the material used (materials of permanent magnets, steel grades, etc.). A cluster of several types of material allows forming a material of stator, rotor (inductor), and radially or axially magnetized magnets [15]. In addition, it was initially assumed that the structure of the obtained translator will be made of simple-form permanent magnets to reduce production costs.

\section{Calculation example}

In the proposed algorithm for a linear electric machine, the design area is divided into a network of finite element cells, with the inherent material of each cell. In this case, six types of materials are considered: air, titanium, and four types of magnet with different magnetization, which are marked as $0,1,2,3,4,5$, respectively (Figure 1). Two initial samples are selected randomly. Further, several cells are selected for exchange by means of homogeneous crossing and as a result two new samples are created. New samples inherit the best characteristics of previous samples, then the process repeats.

Samples are evaluated by the largest value of the objective function, which is the result of calculation of the module of the integral electromagnetic force acting on inductor along the horizontal $\mathrm{X}$ axis. The calculation is performed in the environment of electromagnetic field modeling by the finite element method for magnetostatic problems.

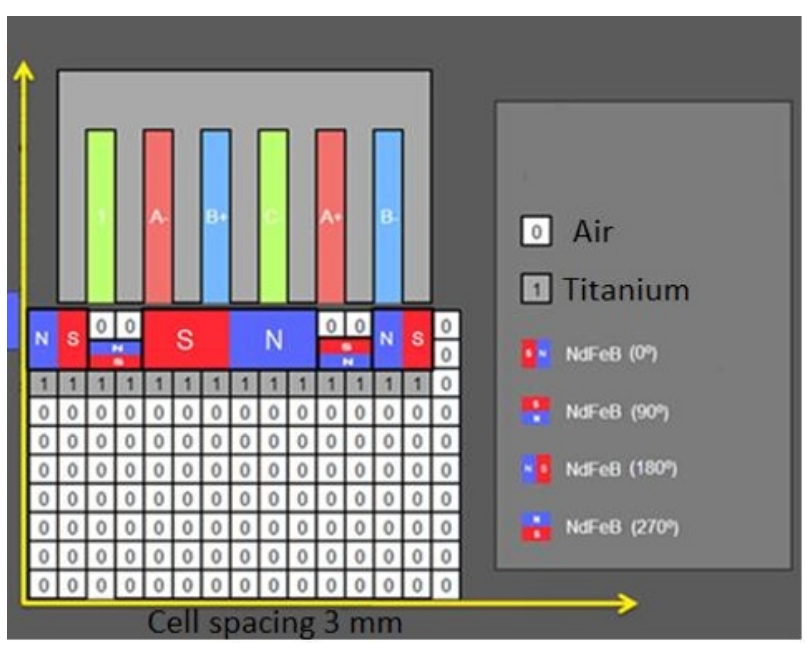

Fig. 1. Holbach Modified Magnetic Assembly.

For physical modeling, a test stand was designed to study the operation of a linear machine module under mechanical, thermal and electrical loads.

The concept of parallel (multi-threaded) calculations is implemented to accelerate the process of optimization the topology of electric machine on the basis of a genetic algorithm.

When writing the program, we selected the integrated development environment Microsoft Visual Basic for Application, which provides ample opportunities to work with the Microsoft Active Field object model for connecting and automating the environment for modeling magnetic fields by the finite element method.

\section{Conclusion}

The results of topological optimization of inductor allowed us to conclude that the maximum electromagnetic force under the given conditions is achieved when the magnets are a modified Holbach assembly obtained as a result of modeling.

Taking into account minimization of the inductor mass, the optimal thickness of magnetic rings in the modified Holbach assembly is $3-6 \mathrm{~mm}$. Under such conditions, the maximum electromagnetic force acting 
on the integral circuit of the inductor in the horizontal direction is achieved.

\section{Acknowledgments}

The publication of the article was carried out within the framework of the project "Creation of a series of electric drives on the basis of Russian high-performance synchronous engines for oil pumping machines using wireless data transmission systems and an adaptive control system for smart deposits", Agreement No. 07411-2018-020 with the Ministry of Education and Science of the Russian Federation of May 30, 2018

\section{References}

1. T.I. Petrov, A.R. Safin, I.V. Ivshin, A.N.Tsvetkov, V.Y. Kornilov, The Prospects of Using a Synchronous Machine with Permanent Magnets in the Oil Industry, 14th International ScientificTechnical Conference on Actual Problems of Electronic Instrument Engineering, Proceedings, 8546157, 336-338 (2018)

2. M.P. Bendsoe, Optimal shape design as a material distribution problem, 193-202 (1989)

3. D.N. Dyck, D.A. Lowther, Automated design of magnetic devices by optimizing material distribution, IEEE Trans. Magn., 32(3), 1188-1193 (1996)

4. D.A. Lowther, W. Mai, D.N. Dyck, A comparison of MRI magnets design using a Hopfield network and the optimized material distribution method, IEEE Trans. Magn., 34(5), 2885-2888 (1998)

5. D.H. Kim, J.K. Sykulski, D.A. Lowther, A novel scheme for material updating in source distribution optimization of magnetic devices using sensitivity analysis, IEEE Trans. Magn., 41(5), 1752-1755 (2005)

6. H. Shim, H. Moon, S. Wang, K. Hameyer, Topology optimization for compliance reduction of magnetomechanical systems, IEEE Trans. Magn., 44(3), 346-351 (2008)

7. D.H. Kim, J.K. Sykulski, D.A. Lowther, The implications of the use of composite materials in electromagnetic device topology and shape optimization, IEEE Trans. Magn., 45(3), 11541157 (2009)

8. J. Lee, N. Kikuchi, Structural topology optimization of electrical machinery to maximize stiffness with body force distribution, IEEE Trans. Magn., 46(10), 3790-3794 (2010)

9. S. Park, S. Min, S. Yamasaki, S. Nishiwaki, J. Yoo, Magnetic actuator design using level set based topology optimization, IEEE Trans. Magn., 44(11), 4037-4040 (2008)

10. S. Park, S. Min, Optimal topology design of magnetic devices using level-set method, IEEE Trans. Magn., 45(3), 1610-1613 (2009)

11. J. Kwack, S. Min, J.P. Hong, Optimal stator design of interior permanent magnet motor to reduce torque ripple using level set method, IEEE Trans. Magn., 46(6), 2108-2111 (2010)

12. J. S. Choi, J. Yoo, Structural topology optimization of magnetic actuators using genetic algorithms and ON/OFF sensitivity, IEEE Trans. Magn., 45(5), 2276-2279 (2009)

13. J. Denies, B. Dehez, H. Ben Ahmed, Simulated annealing and genetic algorithms in topology optimization tools: A comparison through the design of a switched reluctance machine, in Proc. SPEEDAM 2010 - Int. Symp, Power Electronics, Electrical Drives, Automation and Motion, 12471252 (2010)

14. S. Ammous, M. Jebali, N.V. Halima, H.H. Abdallah, A. Oualha, Development of a genetic algorithm for maximizing wind power integration rate into the electric grid, Journal of Renewable and Sustainable Energy, 11(2) (2019)

15. R. Manju Bhashini, K. Ragavan, Magnetic Equivalent Circuit for Surface-Mounted PM Motor (2019), Proceedings of 2018 IEEE International Conference on Power Electronics, Drives and Energy Systems (2018) 